\title{
Comparison of the incidence of skin cancers in patients on dialysis and after kidney transplantation
}

\author{
Joanna Sułowicz'1, Anna Wojas-Pelc ${ }^{1}$, Ewa Ignacak², Katarzyna Krzanowska², Marek Kuźniewski², \\ Władysław Sułowicz ${ }^{2}$
}

${ }^{1}$ Department of Dermatology, Jagiellonian University Medical College, Krakow, Poland ${ }^{2}$ Department of Nephrology, Jagiellonian University Medical College, Krakow, Poland

Adv Dermatol Allergol 2017; XXXIV (2): 138-142

DOI: https://doi.org/10.5114/ada.2017.67078

\begin{abstract}
Introduction: Kidney transplant (KTx) patients on immunosuppressive therapy are predisposed to the development of infections and cancers.

Aim: To compare the incidence and type of malignant skin lesions in kidney transplant patients and the dialyzed population based on the initiated dermatologic screening.

Material and methods: The study included 598 patients: 486 kidney transplant recipients and 112 patients on maintenance dialysis. All the patients underwent dermatological examination. Only histologically confirmed cancers were included in this study. Age, gender and immunosuppressive therapy administration were also considered. Patients were followed up by a dermatologist for a period of 5 years.

Results: Fifty-eight skin cancers; 39 basal cell carcinomas (BCC), 13 squamous cell carcinomas (SCC), 1 Bowen disease, 2 Kaposi sarcoma, 1 malignant melanoma, 1 Merkel cell carcinoma, and 1 fibrosarcoma protuberans were diagnosed in 30 (6.2\%) kidney transplant patients, and 8 lesions (7 BCC and 1 SCC) were found in 4 (3.6\%) patients on dialysis.

Conclusions: The initiated dermatologic screening program indicates that the risk of skin cancer incidence in post kidney transplant patients receiving immunosuppressive therapy was significantly higher than in patients on dialysis.

Key words: dialysis, kidney transplantation, immunosuppression, skin cancer.
\end{abstract}

\section{Introduction}

The population of kidney transplant (KTx) recipients is particularly vulnerable to the development of infectious complications and tumors due to the prolonged use of immunosuppressive drugs [1-3]. Skin tumors represent up to $50 \%$ of all malignancies and their incidence is depended on the geographic region and increases with time from transplantation [4-7]. According to the available literature, the most commonly occurring skin cancers are squamous cell carcinoma (SCC) and basal cell carcinoma (BCC), known collectively as non-melanoma skin cancers (NMSC). In post-transplantation patients, the risk of BCC is 10 times higher and the risk of SCC is up to 250 times higher than in the general population [8]. In case of malignant melanoma (MM), the corresponding risk is up to 8 times higher [9], while for Kaposi's sarcoma (KS) it is up to 20 times higher [10-12].

A limited amount of publications regarding the incidence of malignancies in patients on dialysis and barely any comparative studies of this population to a group of kidney transplant recipients can be found in the available literature [13-15].

\section{Aim}

The study was aimed to compare the incidence as well as type of malignant skin lesions in KTx patients treated with immunosuppression and in patients on maintenance dialysis therapy based on the initiated dermatologic screening program.

\section{Material and methods}

The study was conducted among a group of $598 \mathrm{pa}$ tients on renal replacement therapy. A total of 486 patients: 296 (60.9\%) men and 190 (39.1\%) women aged $46.0 \pm 13.1$ years (range: $18-74$ years) underwent $K T \times$ from a deceased donor. Within the analyzed group, 480 pa-

Address for correspondence: Joanna Sułowicz MD, PhD, Chair and Department of Dermatology, Jagiellonian University Medical College, 8 Skawińska St, 31-066 Krakow, Poland, phone: +48 12 4305266/7400, fax: +48 12 4305266/7422, e-mail: sulowiczj@interia.pl Received: 20.10.2015, accepted: 5.04.2016. 
tients have undergone one transplant, and 6 had two $\mathrm{KTX}$. The mean time from the transplantation procedure to the time of the first dermatological examination was $54.7 \pm 48.8$ months (median: 42.5 , range: $0-298$ months).

The most commonly used immunosuppressive regimens were the combinations including: cyclosporine A (CyA), mycophenolate mofetil (MMF) and steroids - 207 (42.5\%) patients, tacrolimus (TAC) with MMF and steroids - 102 (20.9\%), CyA with azathioprine (AZA) and steroids - 53 (10.9\%) patients, CyA + steroids - 27 (5.6\%), and TAC + steroids - 25 (5.1\%).

Acute rejection occurred in 85 (17.5\%) patients. All of these 85 patients were treated with Solumedrol, while OKT3 and ATG were additionally used in 6 and 4 cases, respectively.

The dialysis group consisted of 112 patients: 57 (50.9\%) men and 55 (49.1\%) women aged $57.4 \pm 15.4$ years (ranging: 22-91 years old) who have not received immunosuppressive therapy prior to dialysis. The average time from initial dialysis to dermatological examination was $63.2 \pm 74.0$ months. Within this group, 87 (77.7\%) patients were treated with hemodialysis (HD), while 25 (22.3\%) patients with peritoneal dialysis.

The study was approved by the Bioethics Committee of the Jagiellonian University (No. KBET/100/B/2006 dated June 29, 2006).

During the first dermatological evaluation, the patient's entire skin surface was carefully examined for all abnormalities. Only histologically confirmed cancers were included in the study. Patients were then followed up for a period of 5 years.

The study was retrospective-prospective.

\section{Statistical analysis}

The obtained results were statistically analyzed using the Student's t-test, Mann-Whitney, $\chi^{2}$ and Fisher tests.
In all of the above tests, the results were statistically significant at $p<0.05$. Statistical analysis was performed using the Statistica 9.0 software (StatSoft).

\section{Results}

In the study population of $486 \mathrm{KT}$ x recipients, skin cancers were diagnosed in 30 patients (Table 1). The most commonly observed skin cancers were NMSC; overall 53 lesions were diagnosed (Table 2). Besides the NMSC we found 2 cases of Kaposi sarcoma, one Merkel cell carcinoma, one malignant melanoma and one fibrosarcoma protuberans. The ratio of BCC : SCC was 2.79, while the ratio of SCC : BCC equaled 0.36 - for the entire population of patients after KTx.

In the group of post-KTx patients, single tumors were present in 11/25 (44.0\%) patients with NMSC - BCC in $7 / 18$ patients (38.9\%), and SCC in 4/10 (40.0\%) patients $(p=1.0)$.

Among the KTx recipients with NMSC, BCC was diagnosed in 15 (60\%) of patients, SCC in 7 (28.0\%), and $3(12.0 \%)$ patients had both types.

In 5 patients, multiple skin lesions were diagnosed during a single visit, while in other cases, numerous changes were observed after an average of 24 months (range: 2-60 months).

Among the dialyzed group, only 8 NMSC were found in $4(3.6 \%)$ patients. Three men and one woman were diagnosed to have 7 cases of BCC and one case of SCC (Table 2). Only single tumors were observed. The ratio of BCC : SCC was $7: 1$, and SCC : BCC $=0.14$ for the entire population of patients on dialysis. All of these patients were treated with hemodialysis.

In both groups, NMSC were mainly localized on the face. The mean age at the time of the first skin cancer diagnosis was lower in $\mathrm{KTx}$ recipients than in dialysis therapy patients ( $59.0 \pm 8.4$ vs. $66.0 \pm 8.5)$; however, the

Table 1. Number and percentage of patients from both studied groups with consecutive skin cancers types

\begin{tabular}{|c|c|c|c|c|}
\hline Type of changes & $\begin{array}{l}\text { Patients after transplantation } \\
\qquad(N=486)\end{array}$ & $\begin{array}{l}\text { Dialyzed patients } \\
\qquad(N=112)\end{array}$ & $P$-value* & $\begin{array}{c}\text { Odds ratio** } \\
\text { (95\% of confidence) }\end{array}$ \\
\hline All skin cancers & $30(6.2 \%)$ & $4(3.6 \%)$ & 0.3 & $6.65(1.45-30.4)$ \\
\hline NMSC: & $25(5.1 \%)$ & $4(3.6 \%)$ & 0.5 & $6.64(1.25-35.2)$ \\
\hline $\mathrm{BCC}$ & $18(3.7 \%)$ & $4(3.6 \%)$ & 0.9 & $6.22(0.94-41.1)$ \\
\hline SCC & $10(2.1 \%)$ & $1(0.9 \%)$ & 0.7 & $5.42(0.43-68.1)$ \\
\hline Bowen disease & $1(0.2 \%)$ & 0 & - & - \\
\hline Merkel cell carcinoma & $1(0.2 \%)$ & 0 & - & - \\
\hline Malignant melanoma & $1(0.2 \%)$ & 0 & - & - \\
\hline Kaposi sarcoma & $2(0.4 \%)$ & 0 & - & - \\
\hline Fibrosarcoma protuberans & $1(0.2 \%)$ & 0 & - & - \\
\hline
\end{tabular}

${ }^{*} \chi^{2}$ test $(d f=1),{ }^{* *}$ odds ratio for transplant and dialysis patients. 
Table 2. Numbers and percentages of neoplastic skin changes

\begin{tabular}{|c|c|c|c|}
\hline Type of changes & $\begin{array}{l}\text { Neoplastic changes in kidney transplant patients } \\
\qquad(N=58)\end{array}$ & $\begin{array}{l}\text { Neoplastic changes in dialyzed patients } \\
\qquad(N=8)\end{array}$ & $P$-value \\
\hline NMSC: & 53 (91.4\%) & $8(100 \%)$ & 1.0 \\
\hline $\mathrm{BCC}$ & 39 (67.2\%) & 7 (87.5\%) & 0.7 \\
\hline SCC & $13(22.4 \%)$ & $1(12.5 \%)$ & 0.7 \\
\hline Bowen disease & $1(1.7 \%)$ & 0 & - \\
\hline Merkel cell carcinoma & $1(1.7 \%)$ & 0 & - \\
\hline Malignant melanoma & $1(1.7 \%)$ & 0 & - \\
\hline Kaposi sarcoma & $2(3.4 \%)$ & 0 & - \\
\hline Fibrosarcoma protuberans & $1(1.7 \%)$ & 0 & - \\
\hline
\end{tabular}

KTx recipients were younger and the observed differences were not statistically significant $(p=0.14)$. The majority of the NMSC lesions in KTx patients (51/53 = $96.2 \%$ change), and all of the lesions in patients on dialysis were diagnosed in subjects aged 50 years and older.

In the group of KTx patients, the first diagnosis of NMSC occurred 2-170 months (median: 74 months) post-transplant surgery and this time did not differ significantly between BCC and SCC ( $p=0.7)$. In the group of dialysis patients, the median time from the start of renal replacement therapy to the diagnosis of the first BCC was 77 months and 132 months for SCC.

\section{Discussion}

The available literature data indicate that the most frequently observed skin cancers among patients after KTX are SCC and BCC $[12,16,17]$. Imko, in their study of KTx patients performed in the Gdansk region, found an almost 205-fold increase in the incidence rate of skin cancers in comparison to the general population [18]. According to the available literature, the risk of posttransplantation skin cancer in the Nordic countries is up to 100 times greater than in the general population, and even up to 250 times higher in Australia, especially in the case of SCC $[19,20]$.

In our study, the incidence of NMSC was higher in post-transplantation patients as compared with the dialysis population. Due to the insignificant number of completed studies on skin cancers comparing dialyzed and post-transplant patients, we encountered difficulties in concluding whether other studies corroborate our results $[14,21,22]$. Although the increased incidence of NMSC in patients with transplanted organs is well documented, there are limited data on skin cancer in dialyzed patients [16, 23]. In a study by Birkeland et al. [13], patients on dialysis and post-KTx had a higher incidence of skin cancer as compared to the general population. We observed non-significant differences in patients' age between the two groups ( $p=0.14$ ) at the time of the first skin cancer diagnosis. The mean age of post-transplant patients at the time of first diagnosis of skin cancer was $59.0 \pm 8.4$ and did not differ from the mean age of the patients included in the study by the Czech researchers; however, it was higher than the age of the patients seen in Imko's study and in studies by other authors [16, 18, 24, 25].

In our study, more than one new case of skin cancer was diagnosed in $56 \%$ of patients with NMSC. Similar results were obtained in the studies conducted by the Expert Group on Renal Transplantation [26]; while in Imko's study, only $22.5 \%$ of patients had multiple lesions [18]. The development of new lesions was observed to occur approximately 24 months (range: 2-60 months) later than in other studies, where new changes occurred on average only after 5 months $[18,27]$. Unlike most studies by other authors [19, 28], we showed a higher incidence of BCC compared to SCC, and gender neutrality against the incidence of skin cancers in KTx patients. Results similar to ours were also obtained by a Spanish group [29].

The incidence of KS in the post-transplant group of patients is 80-500 times higher than in the general population $[12,30]$. The highest incidence is seen in Saudi Arabia - 5.2\% of transplant recipients [12], while in the United States the incidence does not exceed $0.5 \%$ [31]. No accurate data exist on the occurrence of KS in the Polish transplant recipients. In our group of $486 \mathrm{pa}$ tients who underwent KTx, we observed two cases of KS $(0.41 \%)$, while in another retrospective-prospective Polish study from Gdansk, involving a group of 830 renal transplant patients, no single case of KS was found [18]. In the available literature, similarly to our study, KS is more likely to develop in males [12]. Lesions were observed 2 and 9 months post-transplantation, consistently with previous observations which showed that most of the changes appear within 2 years after transplantation [30, 32]. 
In comparison to the results of a study by Piselli et al. [30], in which patients' age in cases of KS ranged from 40 to 59 years, the patients in our study were older, with average age of 51 years. In 60-90\% of KS cases, the lesions are restricted to the skin $[33,34]$, which was confirmed by the results of our research. In case of internal organ involvement, which was not observed in this study, the changes are most commonly localized in the lymph nodes, gastrointestinal tract and lungs [35].

The available literature still questions whether there is an increased risk of malignant melanoma ( $M M)$ in post-organ transplantation patients. To date, in the largest study performed by Lindelöf et al. [20] during a 24year observation period of 5,356 patients, only 6 cases of $M M$ were diagnosed. Based on these findings, it is considered that the risk of MM in transplant patients is comparable to that of the general population. However, according to other authors, the risk is $2-8$ times higher $[9,18,19,28]$. In our study group, we identified only one case of MM, which accounted for $0.2 \%$ of all patients. Analysis of 89 cases of MM in patients from 14 transplant centers working together in the SCOPE (Skin Care in Organ Transplant Recipients, Europe) showed that the average time from organ transplantation to the development of MM was 8.7 years. In our patient, the lesion was found on the left lower extremity, at the age of 58 years, 10 years after transplantation.

There are no conclusive data determining the incidence of MCC in post-transplant patients in the available literature [36]. In a study of 10,955 patients after transplantation conducted by the Cincinnati Transplant Tumor Registry (CTTR), MCC was diagnosed in $0.37 \%$ of patients [37], whereas in our group in $0.2 \%$, and in other studies, it occurred in $0.085 \%$ [38] and $0.071 \%$ [36] of patients.

According to the literature, MCC appeared on average seven years post transplantation (0.4-25 years) and was usually localized on the skin exposed to sunlight [37-39]. In our case, MCC was diagnosed in a 61-year-old female, at 15 months post KTx and was localized on the buttocks. The time from the appearance of the lesion to the distant metastases (liver and periaortic lymph nodes) and patient's death was over 9 months.

Fibrosarcoma protuberans occurred in a 17-year-old male at the permanent catheter exit site. Fibrosarcoma protuberans localization, as previously described in the literature, at the arterio-venous fistula can support the hypothesis that an injury may play a role in the pathogenesis of this disease [40].

\section{Conclusions}

The conducted study demonstrated a significantly higher occurrence of skin cancers among transplant recipients as compared to dialyzed patients. Interestingly, after analyzing the number of cases of particular types of skin cancer in patients receiving immunosuppression, in contrast to most previously published papers from Western Europe and Australia, we found a higher incidence of basal-cell carcinoma than squamous-cell carcinoma.

Our study confirmed that the initiated dermatological screening program among patients on renal replacement therapy is very helpful for early diagnosis of neoplastic skin lesions. This seems particularly important in the view of the constantly growing number of organ transplant patients.

\section{Conflict of interest}

The authors declare no conflict of interest.

\section{References}

1. Rodriguez-Acosta ED, Calva-Mercado JJ, Alberú-Gómez J, et al. Patients with solid organ transplantation and skin cancer: determination of risk factors with emphasis in photoexposure and immunosuppressive regimen. Experience in a third level hospital. Gac Med Mex 2015; 151: 20-6.

2. Tessari G, Naldi L, Boschiero L, et al. Incidence of primary and second cancers in renal transplant recipients: a multicenter cohort study. Am J Transplant 2013; 13: 214-21.

3. Wisgerhof HC, van der Geest LG, de Fijter JW, et al. Incidence of cancer in kidney transplant recipients: a long-term cohort study in a single center. Cancer Epidemiol 2011; 35: 105-11.

4. Einollahi B, Nemeti E, Leksan-Pezeshki M, et al. Skin cancer after renal transplantation: results of a multicenter study in Iran. Ann Transplant 2010; 15: 44-50.

5. Hwang JK, Moon IS, Kim JI. Malignancies after kidney transplantation: a 40-year single-center experience in Korea. Transpl Int 2011; 24: 716-21.

6. Winkelhorst JT, Brokelman WJ, Tiggeler RG, Wobbes T. Incidence and clinical course of de-novo malignancies in renal allograft recipients. Eur J Surg Oncol 2001; 27: 409-13.

7. Wisgerhof HC, Edelbroek JR, de Fijter JW, et al. Subsequent squamous- and basal-cell carcinomas in kidney-transplant recipients after the first skin cancer: cumulative incidence and risk factors. Transplantation 2010; 89: 1231-8.

8. Stockfleth E, Ulrich C, Meyer T, et al. Skin diseases following organ transplantation - risk factors and new therapeutic approaches. Transplant Proc 2001; 33: 1848-53.

9. Le Mire L, Hollywood K, Gray D, et al. Melanoma in renal transplant recipients. Br J Dermatol 2006; 154: 472-7.

10. Campistol JM, Albanell J, Arns W, et al. Use of proliferation signal inhibitors in the management of post-transplant malignancies-clinical guidance. Nephrol Dial Transplant 2007; 22 (Suppl 1): i36-41.

11. Campistol JM, Schena FP. Kaposi's sarcoma in renal transplant recipients - the impact of proliferation signal inhibitors. Nephrol Dial Transplant 2007; 22 (Suppl 1): 17-22.

12. Qunibi W, Akhtar M, Sheth K, et al. Kaposi's sarcoma: the most common tumor after renal transplantation in Saudi Arabia. Am J Med 1988; 84: 225-32.

13. Birkeland SA, Løkkegaard H, Storm HH. Cancer risk in patients on dialysis and after renal transplantation. Lancet 2000; 355: 1886-7.

14. Fischereder M. Cancer in patients on dialysis and after renal transplantation. Nephrol Dial Transplant 2008; 23: 2457-60.

15. Montagnino G, Lorca E, Tarantino A, et al. Cancer incidence in 854 kidney transplant recipients from a single institution: 
comparison with normal population and with patient under dialytic treatment. Clin Transplant 1996; 10: 461-9.

16. Stewart JH, Vajdic CM, van Leeuwen MT, et al. The pattern of excess cancer in dialysis and transplantation. Nephrol Dial Transplant 2009; 24: 3225-31.

17. Savoia P, Stroppiana E, Cavaliere G, et al. Skin cancers and other cutaneous diseases in renal transplant recipients: a single Italian center observational study. Eur J Dermato 2011; 21: 242-7.

18. Imko-Walczuk B. Valuation of menace of neoplastic diseases and possibilities of its prevention in kidney transplant patients [Polish]. Doctoral thesis. Gdansk 2009.

19. Bouves Bavinck JN, Hardie DR, Green A, et al. The risk of skin cancer in renal transplant recipients in Queensland Australia. Transplantation 1996; 61: 715-21.

20. Lindelöf B, Sigurgeirsson B, Gäbel H, Stern RS. Incidence of skin cancer in 5356 patients following organ transplantation. Br J Dermatol 2000; 143: 513-9.

21. Maisonneuve P, Agodoa L, Gellert R, et al. Cancer in patients on dialysis for end-stage renal disease: an international collaborative study. Lancet 1999; 354: 93-9.

22. Miach PJ, Dawborn JK, Xipell J. Neoplasia in patients with chronic renal failure on long-term dialysis. Clin Nephrol 1976 5: 101-4.

23. Mackenzie KA, Wells JE, Lynn KL, et al. First and subsequent nonmelanoma skin cancers: incidence and predictors in a population of New Zealand renal transplant recipients. Nephrol Dial Transplant 2010; 25: 300-6.

24. Imko-Walczuk B, Ankudowicz A, Jaśkiewicz J, et al. Skin cancer in organ transplant recipients [Polish]. Przegl Dermatol 2011; 98: 91-103.

25. Berg D, Otley CC. Skin cancer in organ transplant recipients: epidemiology, pathogenesis, and management. J Am Acad Dermatol 2002; 47: 1-17.

26. EBPG Expert Group on Renal Transplantation. European best practice guidelines for renal transplantation. Cancer risk after renal transplantation. Skin cancer prevention and treatment. Nephrol Dial Transplant 2002; 17: 31-6.

27. Euvrard S, Kanitakis J, Decullier E, et al. Subsequent skin cancers in kidney and heart transplant recipients after the first squamous cell carcinoma. Transplantation 2006; 81: 1093-100.

28. Moloney FJ, Comber H, O'Lorcain P, et al. A population-based study of skin cancer incidence and prevalence in renal trans plant recipients. Br J Dermatol 2006; 154: 498-504.

29. Bernat Garcia J, Morales Suarez-Varela M, Vilata JJ, et al. Risk factors for non-melanoma skin cancer in kidney transplant patients in a Spanish population in the Mediterranean region. Acta Derm Venerol 2013; 93: 422-7.

30. Piselli P, Busnach G, Citterio F, et al. Risk of Kaposi sarcoma after solid-organ transplantation: multicenter study in 4,767 recipients in Italy, 1970-2006. Transplant Proc 2009; 41: 122730.

31. Mbulaiteye SM, Engels EA. Kaposi's sarcoma risk among transplant recipients in the United States (1993-2003). Int J Cancer 2006; 119: 2685-91.

32. Tessari G, Naldi L, Boschiero L, et al. Incidence and clinical predictors of Kaposi's sarcoma among 1721 Italian solid organ transplant recipients: a multicenter study. Eur J Dermatol 2006; 16: 553-7.

33. Bencini PL, Montagnino G, Citerio A, et al. Cutaneous abnormalities in uremic patients. Nephron 1985; 40: 316-21.
34. Bętkowska-Prokop A, Sułowicz J, Sobaszek-Pitas M, Sułowicz W. Kaposi's sarcoma in solid organ recipients. Przegl Lek 2010; 67: 475-8.

35. El-Agroudy AE, El-Baz MA, Ismail AM, et al. Clinical features and course of Kaposi's sarcoma in Egyptian kidney transplant recipients. Am J Transplant 2003; 3: 1595-9.

36. Koljonen V, Kukko H, Tukiainen E, et al. Incidence of Merkel cell carcinoma in renal transplant recipients. Nephrol Dial Transplant 2009; 24: 3231-5.

37. Penn I, First MR. Merkel's cell carcinoma in organ recipients: report of 41 cases. Transplantation 1999; 68: 1717-21.

38. Kanitakis J, Euvrard S, Chouvet B, et al. Merkel cell carcinomas developing in organ transplant recipients: report of two cases with unusual histological features and literature review. J Cutan Pathol 2006; 33: 686-94.

39. Buell JF, Trofe J, Hanaway MJ, et al. Immunosuppression and Merkel cell cancer. Transplant Proc 2002; 34: 1780-1.

40. Piciotto F, Basolo B, Massara C, et al. Dermatofibrosarcoma protuberans at the site of arteriovenous fistula in renal transplant recipients. Transplantation 1999; 68: 1074-5. 